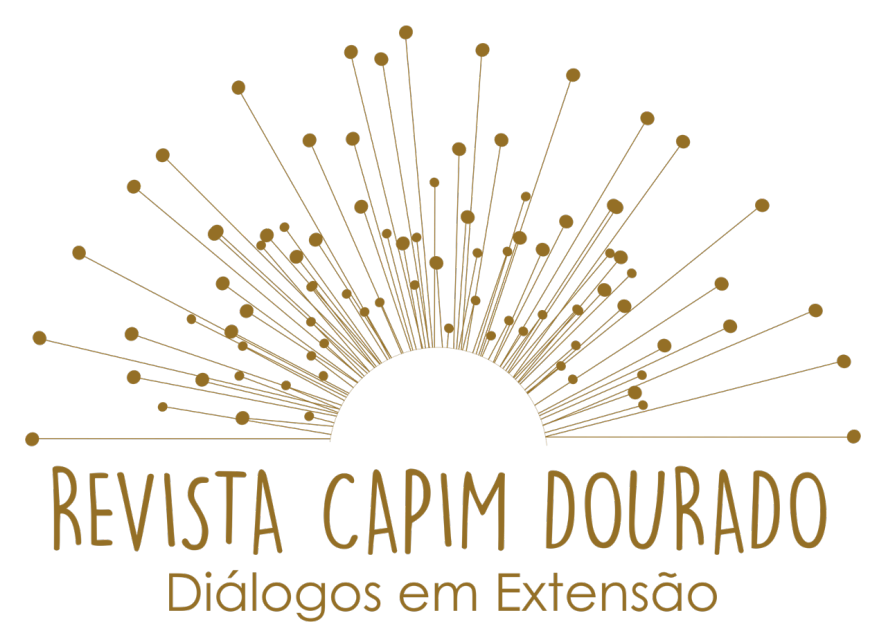

ISSN n² 2595-7341

Vol. 3, n. 1, Janeiro-Abril, 2020

DOI: http://dx.doi.org/10.20873/uft.2595-7341.2020v3n1p133

\title{
COMPARTILHANDO SABERES DA PRÁTICA DOCENTE: O FOCO NA REDAÇÃO
}

SHARING KNOWLEDGE OF TEACHING PRACTICE: THE FOCUS ON WRITING

COMPARTIR EL CONOCIMIENTO DE LA PRÁCTICA DOCENTE: EL ENFOQUE DE LA ESCRITURA

\section{Ricardo Ferreira de Sousa ${ }^{1}$ \\ Radamés Vieira Nunes ${ }^{2}$}

\section{RESUMO}

O presente relato de experiência versa-se acerca do trabalho desenvolvido para o Programa de Acesso Democrático à Universidade e Apoio Pedagógico ao longo do ano de 2018, projeto de extensão certificado pela Universidade Federal do Tocantins, campus de Porto Nacional, Tocantins. Aqui, evidenciamos um breve relato de experiência em torno da prática de ensino para o componente curricular de redação. Nosso objetivo é refletir e discutir acerca da importância da monitoria como espaço inicial de formação para a docência, considerando o processo de ensino-aprendizagem e de interação verbal. Nesse intuito, a monitoria é um programa que tem como foco principal, proporcionar que os alunos adquiram experiência na docência, uma vez que os monitores procedem diretamente na prática de ensino em sala de aula. Diante dessa hipótese, 0

\footnotetext{
${ }^{1}$ Graduação em Letras - Língua Portuguesa e Literaturas pela Universidade Federal do Tocantins (UFT), Porto Nacional, Tocantins. ricardof@mail.uft.edu.br.

2 Professor Doutor adjunto do curso de História da Universidade Federal do Tocantins (UFT) e coordenador do Programa de Apoio Democrático à Universidade e Apoio Pedagógico (PADU), Porto Nacional, Tocantins. radamesnunes@mail.uft.edu.br.
} 


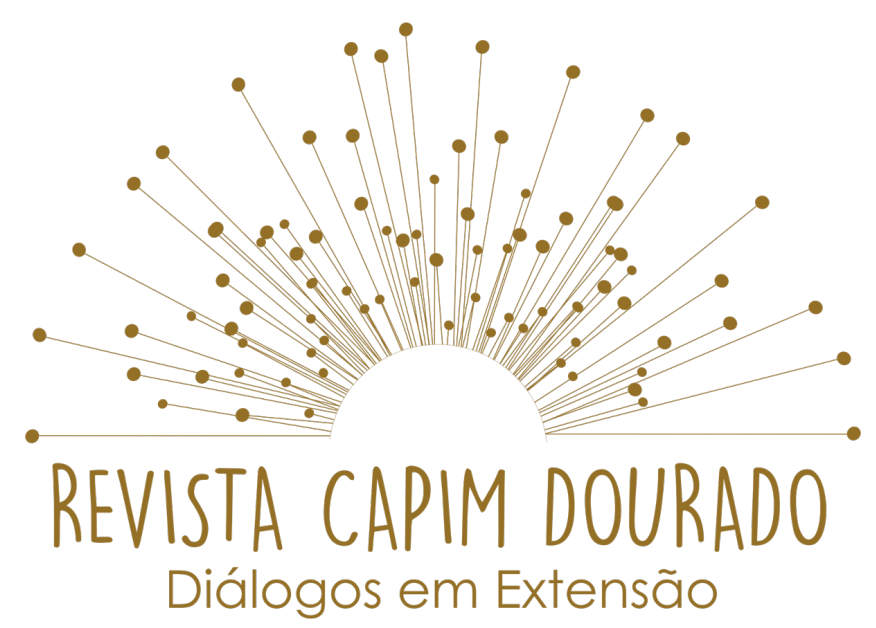

ISSN n² 2595-7341

Vol. 3, n. 1, Janeiro-Abril, 2020

DOI: http://dx.doi.org/10.20873/uft.2595-7341.2020v3n1p133

trabalho com a produção textual como foco deste relato, deve ser realizado de forma cuidadosa pelo monitor, pois as estruturas linguístico-textuais nem sempre são assimiladas em tempo hábil pelos alunos, reflexo da pouca prática de leitura e escrita, que levam alguns alunos a cometerem erros ortográficos e gramaticais. Assim, o monitor vem colaborar com o desempenho do ensino e aprendizado logo que um processo não garante o sucesso do outro -, mediando à comunicação entre os sujeitos envolvidos na disciplina.

PALAVRAS-CHAVE: Teoria e Prática. Experiência. Ensino. Prática Docente.

\section{ABSTRACT}

This experience report is about the work developed for the Program for Democratic Access to University and Pedagogical Support throughout 2018, an extension project certified by the Federal University of Tocantins, campus of Porto Nacional, Tocantins. Here, we present a brief report of experience around teaching practice for the curricular component of writing. Our goal is to reflect and discuss the importance of monitoring as an initial training space for teaching, considering the teaching-learning process and verbal interaction. In this sense, the monitoring is a program that has as main focus, providing that the students acquire experience in teaching, since the monitors proceed directly in the teaching practice in the classroom. In view of this hypothesis, the work with textual production as the focus of this report, must be carried out carefully by the monitor, as the linguistic-textual structures are not always assimilated in a timely manner by students, reflecting the little practice of reading and writing, which lead some students to make spelling and grammatical errors. Thus, the monitor comes to collaborate with the performance of teaching and learning - as soon as one process does not guarantee the success of the other -, mediating communication between the subjects involved in the discipline. 


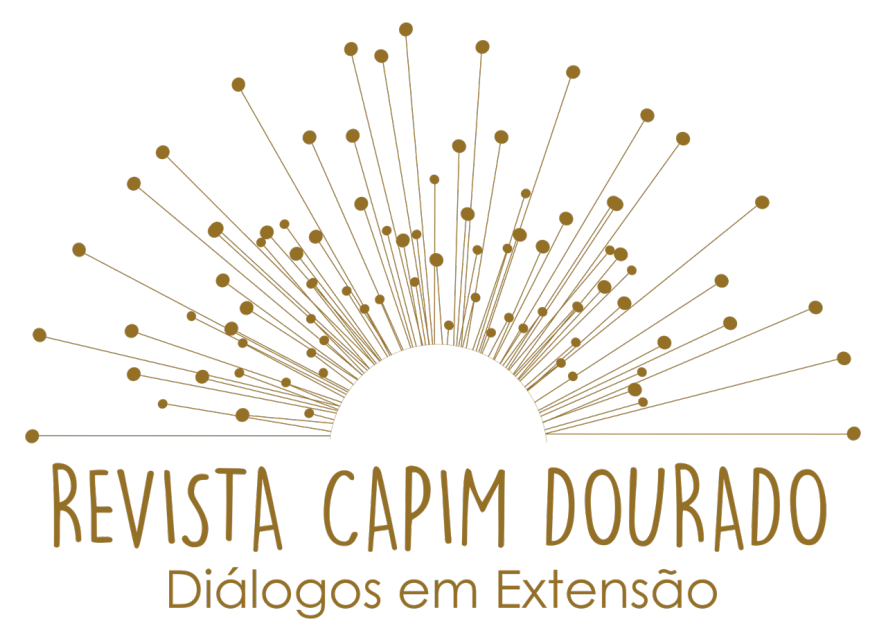

ISSN n² 2595-7341

Vol. 3, n. 1, Janeiro-Abril, 2020

DOI: http://dx.doi.org/10.20873/uft.2595-7341.2020v3n1p133

KEYWORDS: Theory and Practice. Experience. Teaching. Teaching Practice.

\section{RESUMEN}

Este relato de experiencia trata sobre el trabajo desarrollado para el Programa de Acceso Democrático a la Universidad y Apoyo Pedagógico a lo largo de 2018, proyecto de extensión certificado por la Universidad Federal de Tocantins, campus de Porto Nacional, Tocantins. A continuación, presentamos un breve informe de la experiencia en torno a la práctica docente para el componente curricular de la escritura. Nuestro objetivo es reflexionar y discutir la importancia del seguimiento como espacio de formación inicial para la docencia, considerando el proceso de enseñanza-aprendizaje y la interacción verbal. En este sentido, el seguimiento es un programa que tiene como foco principal, siempre que los estudiantes adquieran experiencia en la docencia, ya que los monitores proceden directamente en la práctica docente en el aula. Ante esta hipótesis, el trabajo con la producción textual como foco de este informe, debe ser realizado con cuidado por el monitor, ya que las estructuras lingüísticotextuales no siempre son asimiladas de manera oportuna por los estudiantes, reflejando la poca práctica de la lectura y la escritura, que llevar a algunos estudiantes a cometer errores ortográficos y gramaticales. Así, el monitor viene a colaborar con el desempeño de la enseñanza y el aprendizaje -en cuanto un proceso no garantiza el éxito del otro-, mediando la comunicación entre los sujetos involucrados en la disciplina.

PALABRAS CLAVE: Teoría y Práctica. Experiencia. Enseñando. Práctica docente.

Recebido em: 01.10.2019. Aceito em: 09.10.2019. Publicado em: 01.01.2020. 


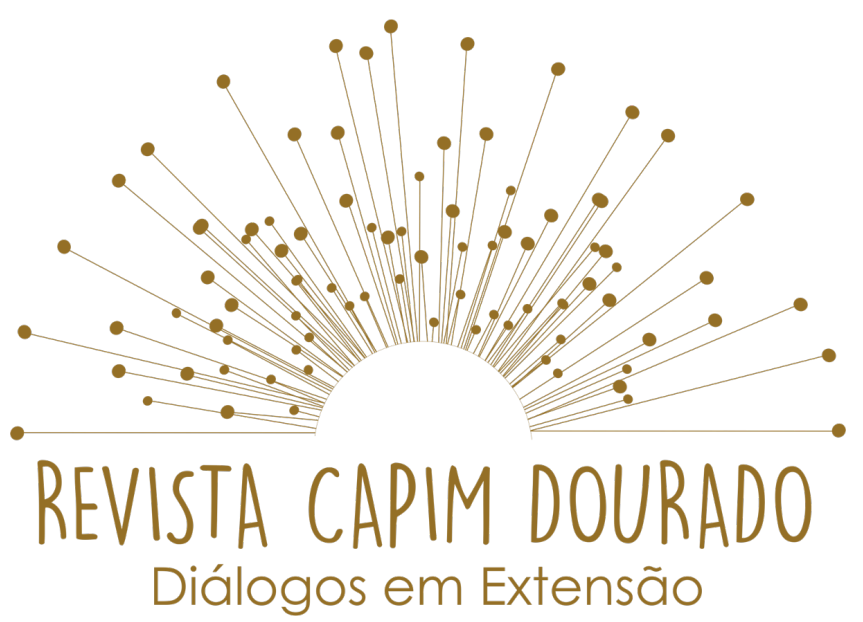

ISSN n² 2595-7341

Vol. 3, n. 1, Janeiro-Abril, 2020

DOI: http://dx.doi.org/10.20873/uft.2595-7341.2020v3n1p133

\section{INTRODUÇÃO}

O presente trabalho relata minha experiência vivenciada a partir da monitoria para o Programa de Acesso Democrático à Universidade e Apoio Pedagógico (PADU) realizada em uma escola da rede pública de ensino situada na zona urbana da cidade de Porto Nacional/TO.

Este relato tem como objetivo compartilhar experiências da prática docente desenvolvida no componente curricular denominado Redação para o projeto de extensão da Universidade Federal do Tocantins (UFT), contribuindo assim para que haja de modo significativo, uma reflexão acerca da formação docente e da extensão universitária.

Neste relato, trago algumas reflexões e apontamentos sobre ser professor, a prática no ensino dos conteúdos e a relação-interação com os alunos no cotidiano escolar que essa experiência tem me proporcionado.

\section{METODOLOGIA}

O Padu foi realizado na escola pública Centro de Ensino Médio Félix Camoa, do município de Porto Nacional, estado do Tocantins, localizado na Avenida Tocantins, S/N, Setor Vila Nova. O projeto visa promover a igualdade de acesso e de oportunidade para ingresso no ensino superior, de modo que possa minimizar as consequências de um processo histórico de exclusão social, que afasta os menos favorecidos da Universidade pública. Assim, o público alvo do 


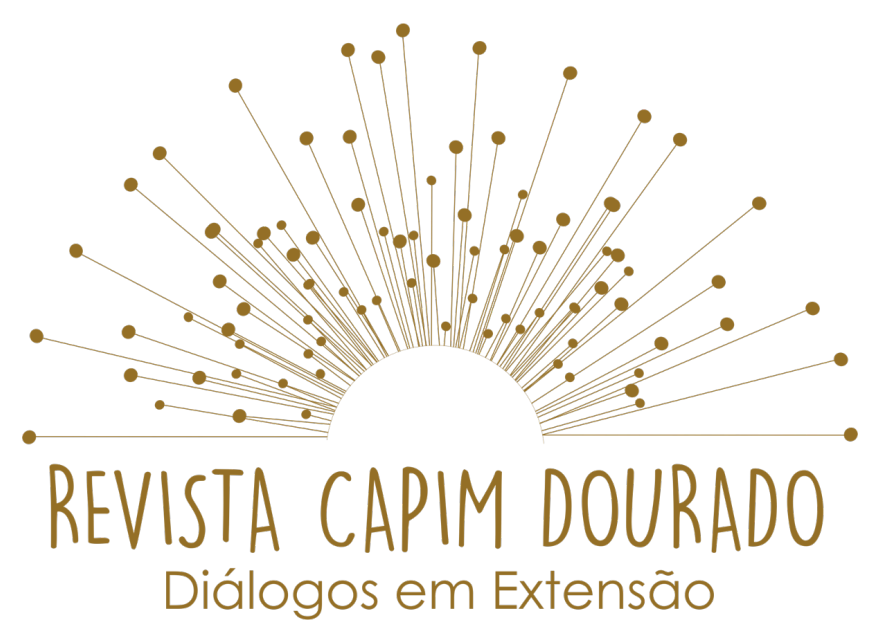

ISSN n² 2595-7341

Vol. 3, n. 1, Janeiro-Abril, 2020

DOI: http://dx.doi.org/10.20873/uft.2595-7341.2020v3n1p133

projeto são alunos em situação de vulnerabilidade socioeconômica, oriundos de escolas públicas. Com isso, a edição do Padu 2018 atendeu duas turmas que respectivamente formada com 35 e 43 alunos, onde em ambas as turmas foram ministradas a disciplina de Redação. As aulas tiveram um período de duração de seis meses sendo que a disciplina de redação foi realizada nas quartas-feiras, totalizando dezessete encontros presenciais.

As aulas foram dialogadas e expositivas, focando no processo interacionista, fazendo uso de textos impressos, no qual realizamos debates sobre possíveis temas para a redação do Exame Nacional do Ensino Médio (ENEM) e prática de produção de texto atendendo a proposta da estrutura linguístico-textual.

O aporte metodológico usado neste trabalho foi o bibliográfico, atrelado com relatos de experiências que são disponibilizados no decorrer do texto. Segundo Marconi e Lakatos (2010) "pesquisa bibliográfica não é mera repetição do que foi dito ou escrito sobre certo assunto, mas propicia o exame de um tema sob novo enfoque ou abordagem, chegando a conclusões inovadoras". A seguir, é demostrado como ocorre o processo de monitoria, especificamente, na monitoria do Padu e da abordagem prática de ensino adotada.

\section{FUNDAMENTAÇÃO TEÓRICA}




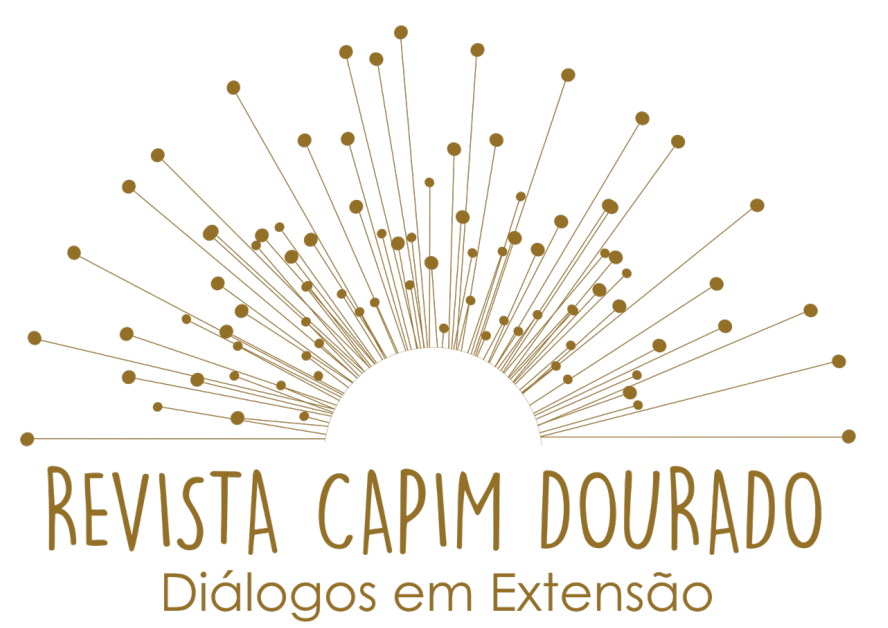

ISSN n² 2595-7341

Vol. 3, n. 1, Janeiro-Abril, 2020

DOI: http://dx.doi.org/10.20873/uft.2595-7341.2020v3n1p133

O programa de monitoria tem como foco principal, proporcionar que os monitores adquiram experiência na docência de modo que contribua para o processo de ensino e aprendizagem. Conforme Schneider (2003), o trabalho com a monitoria consiste numa atividade acadêmica de natureza formativa, pois caminha para o desenvolvimento de competências pedagógicas assim como, também, auxilia os acadêmicos na construção de ideias, conceitos e na produção de conhecimento.

O público alvo deste programa no geral, especificamente, foram alunos pré-vestibulandos em busca de uma aprovação em concurso público ou conseguir aprovação em um curso superior, e a disciplina de redação, a qual tem por intuito, trabalhar o básico da linguística textual, permite que os alunos frequentes possam conhecer e aplicar as estruturas básicas do texto e componentes das palavras da língua portuguesa, bem como, ter domínio dos mecanismos de coesão e coerência e sua importância para a construção de sentidos do texto. Além disso, a referida disciplina se ocupa da articulação e organização das palavras nos enunciados, assim como, ter maior propriedade das formas de organização da língua materna.

Nesse sentido, remetemos a produção escrita como um ato de consequência, pois para Sercundes (1999, p. 95) este tem "como ponto de partida o saber oral que conduzirá a uma escrita, a um registro, muitas vezes homogeneizado desse saber, verificando-se que esse registro é consequência do trabalho realizado". Para aproximar a produção escrita das necessidades 


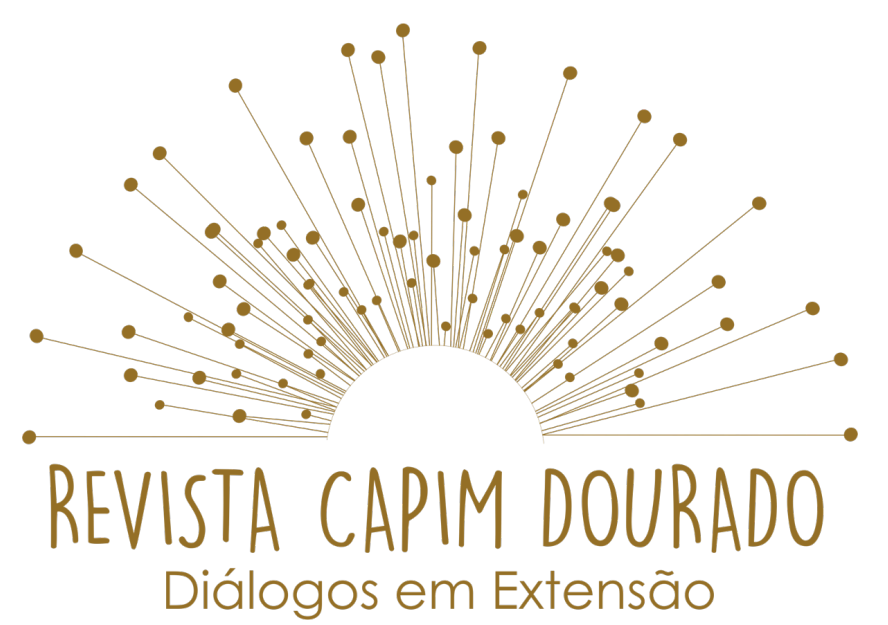

ISSN n² 2595-7341

Vol. 3, n. 1, Janeiro-Abril, 2020

DOI: http://dx.doi.org/10.20873/uft.2595-7341.2020v3n1p133

enfrentadas no dia a dia, o caminho geralmente é enfocar o desenvolvimento dos comportamentos leitores e escritores.

Geraldi (1992) enfatiza que quando o professor simplesmente pede que - aluno escreva sem que subsídios conceituais e metodológicos sejam trabalhados, além das condições de produção (ter o que dizer; ter para quem dizer; desenvolver estratégias adequadas), o aluno está simplesmente trabalhando a redação e não a produção textual. Assim, a aula, remete à artificialidade da produção, não se levando em conta os aspectos sócio-históricos que devem estar presentes quando pensamos na linguagem como forma de interação social.

Por esse motivo, cabe ao mediador articular melhor os objetivos propostos para a aula e a mediação deve ser construída com base no diálogo coletivo, entre professor e aluno, de modo que devem ser pensadas algumas estratégias com a finalidade de intervir em possíveis carências ao longo do percurso. Logo, o emprego de uma linguagem mais didática, mais próxima do contexto do aluno, a exemplificação mais sucinta, um atendimento exclusivo para cada discente, contribui significativamente para uma melhor aprendizagem.

\section{RESULTADOS FINAIS}

Sabemos que na educação básica, por diversos motivos, a produção textual não é empregada na quantidade e forma adequada de maneira que prepare o indivíduo para sua possível prática acadêmica. $O$ ensino apresenta 


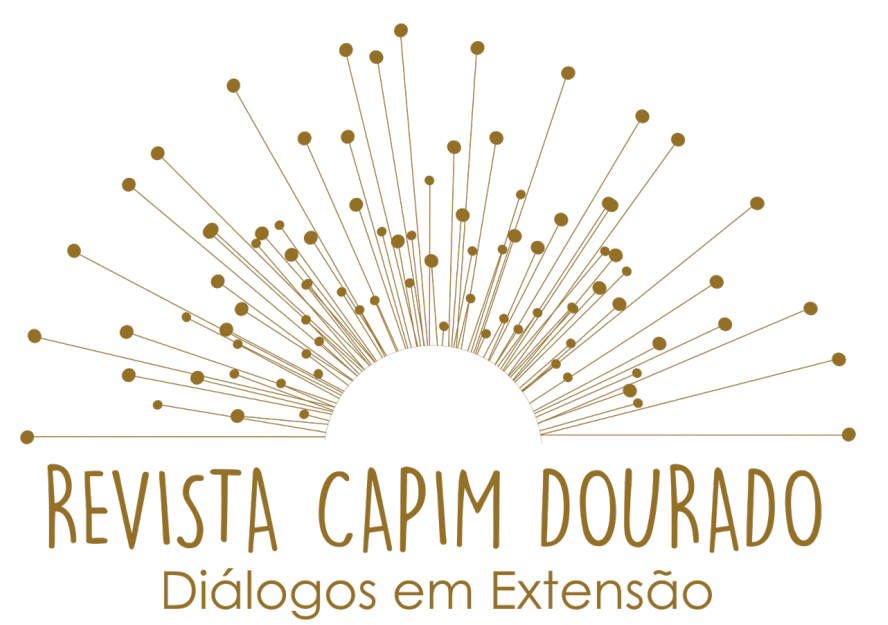

ISSN n² 2595-7341

Vol. 3, n. 1, Janeiro-Abril, 2020

DOI: http://dx.doi.org/10.20873/uft.2595-7341.2020v3n1p133

falhas que são mais percebidas quando chega o momento de mostrar uma competência e/ou habilidade que, infelizmente, não foi desenvolvida no tempo adequado. Assim, possibilitar ao aluno a discussão e produção de textos que the serão cobrados é uma forma de investimento intelectual disponível para todos àqueles que precisam amenizar as angústias e inquietações pelas quais se passa num primeiro momento.

Com isso, para o desenvolvimento das aulas e atendendo a proposta do projeto, a metodologia empregada inicia-se por meio de cunho expositivoparticipativo, convocando os alunos a contribuírem na construção do conhecimento, de maneira que possibilite sua apropriação das produções que the são requeridas. Em seguida, primamos por desenvolver com os alunos a prática de produção textual, com temas previamente definidos e que atendessem a proposta de redação do Enem, uma vez que o curso tem como fim ajudá-los a produzirem e veicularem o conhecimento apreendido durante seu percurso escolar em forma de texto escrito e oral. Ler, interpretar e produzir textos são habilidades que perpassam todas as áreas do conhecimento e, portanto, é importante que promova o seu desenvolvimento para tal requisito.

Nesse intento, ao longo dos encontros foi possível notar avanços significativos na compreensão e desenvolvimento dos conteúdos da disciplina, o que resultou positivamente no aprendizado dos alunos. Percebe-se que a falta de prática de leitura e escrita levam alguns alunos a cometerem erros ortográficos e gramaticais, que por vez são ocasionados devido ao pouco conhecimento de mundo e repertório linguístico. Dessa forma, é de grande saber a integração do 


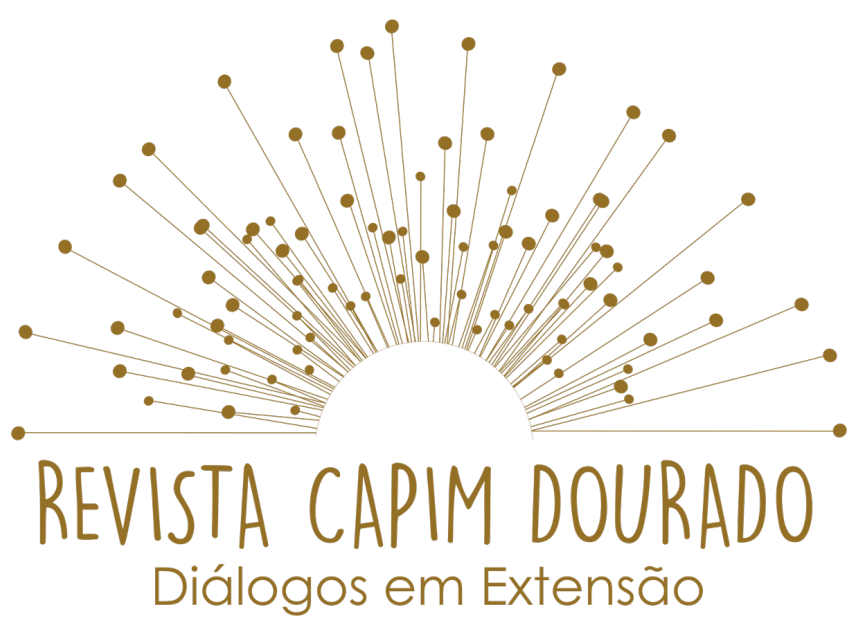

ISSN n² 2595-7341

Vol. 3, n. 1, Janeiro-Abril, 2020

DOI: http://dx.doi.org/10.20873/uft.2595-7341.2020v3n1p133

aluno na prática escolar, pois é neste ambiente que este irá tirar suas dúvidas, colocando a teoria em prática e se descobrindo como o mais novo agente versado na prática de produção de textos, obtendo assim bons resultados diante de seleções e outros meios nos quais exigem domínio e argumentação.

\section{CONSIDERAÇÕES FINAIS}

As práticas vividas durante a monitoria são marcas que, certamente, ficam impressas no intelecto de quem teve o privilégio de vivenciar essa realidade. Os ensinamentos integram-se à carga intelectual e social do aluno monitor, revelando-lhe novos horizontes e perspectivas acadêmicas.

A partir dos resultados podemos perceber que a monitoria veio agregar na prática, promovendo conhecimentos acerca da construção profissional, de modo que isso se deu mediante a união da teoria e prática. Com essa experiência fica clara a necessidade de estarmos constantemente buscando rever nossos conhecimentos, saberes, metodologias e estratégias para que o processo de ensino-aprendizagem seja significativo tanto para os alunos como para os profissionais da educação.

\section{REFERÊNCIAS}

MARCONI, M. de A. LAKATOS, E. M. Metodologia Científica. 5 ed. São Paulo: Atlas, 2010. 


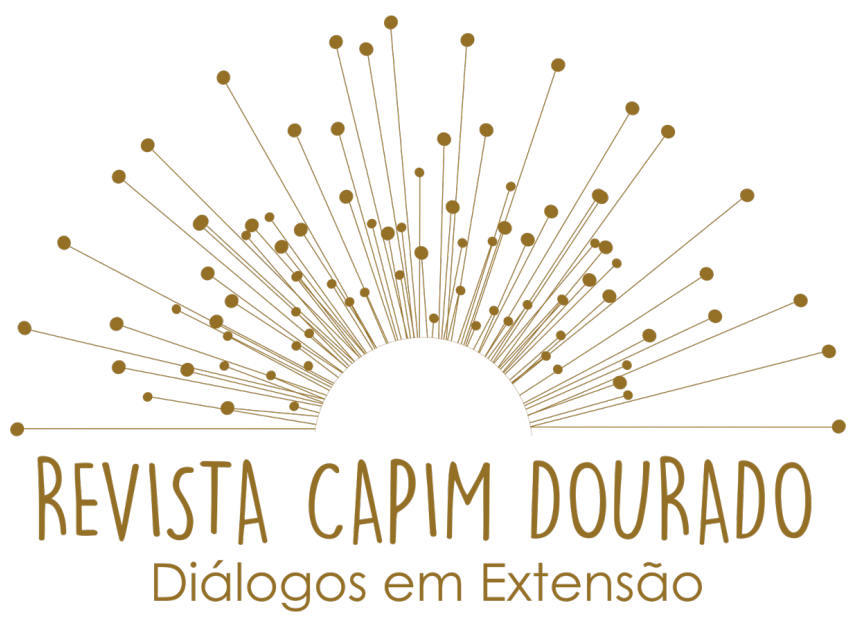

ISSN n² 2595-7341

Vol. 3, n. 1, Janeiro-Abril, 2020

DOI: http://dx.doi.org/10.20873/uft.2595-7341.2020v3n1p133

SERCUNDES, M. M. I. Ensinando a escrever. In. GERALDI, J. W.; CITELLI, G. Aprender e ensinar com textos de alunos. Vol. 1. São Paulo: Cortez, 1997.

SCHNEIDER, M. S. P. S. Monitoria: Instrumento para trabalhar com a diversidade de conhecimento em sala de aula. Revista Espaço Acadêmico, V. Mensal, 2006. 